Brasil: dilemas e desafios 



\title{
Brasil, século XXI
}

\author{
HELIO JAGUARIBE
}

$\mathrm{N}$

ESTE BREVE estudo busca-se inicialmente identificar e analisar, de forma extremamente sucinta, os principais problemas com que se defronta o Brasil ao ingressar no século XXI. Parte-se da constatação de que o país não logrou, ao se encerrar o século XX, superar seu histórico subdesenvolvimento, embora tenha alcançado significativos resultados econômicos e infra-estruturais, de tal sorte que se tornou viável, se apropriadas medidas forem consistentemente adotadas, dentro de um par de decênios atingir esse longamente perseguido objetivo. A seguir, são sucintamente discutidos os problemas de relativamente curto prazo, correspondentes aos três últimos anos do governo Cardoso, e os problemas de longo prazo, a serem atacados no curso do novo século.

\section{Brasil 2000}

O Brasil ingressou no ano 2000 tendo razoavelmente se recuperado da crise de desvalorização do real, de janeiro de 1999. As previsões mais pessimistas, que contavam com significativa queda do PIB, elevada inflação e decorrente alta do dólar, não se realizaram. O PIB deverá ter um mínimo incremento - embora se tenha deteriorado o PIB per capita - a inflação ficou (IPCA) em torno de $8 \%$ e o dólar comercial se estabilizou na faixa de R\$ 1,80 . Acrescente-se que as contas do setor público se encerraram, em 1999, incluída a Previdência, com um superávit primário da ordem de R\$ 30 bilhões, correspondente a $3 \%$ do PIB. A dívida pública, fora do Banco Central, situou-se em torno de R 412 bilhões, representando cerca de $40 \%$ do PIB. A balança comercial se encerrou em déficit, a despeito da desvalorização, correspondendo o déficit em conta corrente a cerca de $4,4 \%$ do PIB.

$\mathrm{Na}$ área social houve importante melhoria no setor educacional. Em 1999 97,5\% das crianças tinham acesso à escola, contra 86\% em 1990. O analfabetismo, até 16 anos, caiu para menos de $5 \%$, concentrando-se a ileteraticidade na população mais velha, sendo o total, para todas as idades, de $12 \%$. A matriculação secundária registrou, no período 1995 a 1999, significativo aumento de $40 \%$. O setor saúde, apesar das precárias condições da maioria dos hospitais, também registrou progressos. Entre outros dados, o número de agentes comunitários se elevou em 1999 para cerca de 100 mil, contra apenas 22 mil em 1995. 
Politicamente, entretanto, o ano de 1999 se assinalou por grande e brusca queda da popularidade do presidente Cardoso. Tendo acabado de se reeleger, logo no primeiro turno por maioria absoluta de votos, o impacto negativo da desvalorização, multiplicado por expectativas muito pessimistas, intensivamente exploradas pela oposição e pelos meios de comunicação, derrubaram a imagem do presidente. Cardoso reagiu lançando, com o Plano-Plurianual para 2000-2003, um grande programa de desenvolvimento econômico-social, prevendo inversões de ordem de R $\$ 170$ bilhões, cerca de $70 \%$ das quais pelo setor privado e assegurando que o país iria entrar, estavelmente, numa fase de desenvolvimento sustentável. Ao se iniciar o ano 2000 a impopularidade do presidente Cardoso, apresentou indicações de se reduzir.

\section{Problemas mais imediatos}

O Brasil ingressa no século XXI, como precedentemente se mencionou, sem ter resolvido o grande desafio histórico de seu subdesenvolvimento. Um subdesenvolvimento que se caracteriza, principalmente, pela imensa brecha que separa uma minoria de cidadãos educados e dotados de condições de vida equivalentes às dos países centrais, representando algo como $30 \%$ da população total, da grande maioria dos deseducados e pobres. Dentre estes, 14\% das famílias encontram-se em estado de miséria e $31 \%$ de grande pobreza. Essa imensa desigualdade é também regional e rural, situando-se a maioria da população carente no Nordeste e no campo, ademais de nos bolsões metropolitanos de miséria. Por outro lado, embora os padrões médios dos setores e estratos modernos do Brasil comparem-se vantajosamente com os do sul da Europa, é apreciável a decalagem tecnológica do país relativamente aos países de vanguarda.

Ademais de ter pela frente a grande tarefa de superar seu subdesenvolvimento, ao iniciar-se o século XXI o Brasil se defronta com sérios problemas de curto e médio prazos, sem a solução dos quais não é viável o desenvolvimento do país. Os problemas mais imediatos são, em última análise, de duas ordens: econômico-financeiros e político-institucionais.

No âmbito econômico-financeiro o Brasil sofre o constrangimento de dois renitentes déficits: o do balanço de pagamentos e o das contas da União. Cronicamente deficitário no balanço de serviços, o país passou vários anos em déficit na sua balança de comércio, possivelmente corrigível a partir de 2000, ocasionando em 1999 um déficit no balanço de pagamentos da ordem de $4 \%$ do PIB. O déficit líquido do setor público, devido, principalmente, ao desequilíbrio das contas da previdência e aos altos juros da dívida 
interna, a despeito de um superávit primário da ordem de $3 \%$ do PIB, atingiu mais de 7\% em 1999.

Existe, entre esses dois déficits, uma relação perversa. Se, para reduzir o déficit das contas públicas, se abaixa a taxa de juros, reduz-se, correspondentemente, a atratividade para capitais externos, agravando a situação do balanço de pagamentos. Se os juros são majorados, para atrair capitais externos, eleva-se o déficit das contas públicas.

Em tal situação, a única solução possível é de caráter positivo, ou seja, a adoção de medidas que, por um lado, incrementem substancialmente as exportações e mantenham as importações em nível moderado e, por outro, regularizem as contas públicas, mediante reformas tributária e previdenciária que equilibrem as contas do INSS e, com a minimização dos gastos de custeio, gerem confortável superávit para inversões da União.

A segunda ordem de problemas mais imediatos refere-se a questões institucionais e políticas, que afetam, de forma extremamente séria, a governabilidade do país. Presentemente, o Brasil é quase ingovernável. A crise de governabilidade provém de graves defeitos dos sistemas político e institucional.

As deficiências do sistema político decorrem, principalmente, do inadequado regime eleitoral e do ainda menos adequado regime de regulação dos partidos políticos. O atual regime regulador dos partidos políticos permite e de certa forma favorece uma infinita proliferação de legendas, destituídas de qualquer efetiva significação pública, que se convertem em máquinas de mercantilização política, na grande maioria dos casos. Os partidos são siglas privadas de significação, relativamente às quais os políticos se ligam e se desligam ao sabor de ocasionais interesses eleitorais, entre outros. O regime eleitoral vigente favorece a eleição de candidatos desprovidos de qualquer significação pública, que exercerão seu mandato apenas em função de seus interesses pessoais. Daí a falta de orientação programática e a dificuldade de formar maiorias consistentes, em cada legislatura, forçando o Executivo a barganhar com cada parlamentar, individualmente, as medidas que julgue de interesse público.

A outra dimensão da ingovernabilidade decorre, ademais de outros aspectos, do fato de a Constituição vigente ter sido originariamente concebida para regular um regime parlamentar e, à última hora, sem modificação do texto preexistente, nela se ter implantado um regime presidencialista. Daí profundas incongruências entre as atribuições do Congresso, inicialmente concebido para ser o principal poder da República, e as atribuições 
do presidente, que se tornou na prática - a despeito das aparências de poder que lhe confere a faculdade de emitir medidas provisórias - refém de um parlamento cujos poderes não correspondem às suas responsabilidades públicas e que goza de indissolubilidade.

A ingovernabilidade brasileira, embora presentemente em parte contornada pela excepcional paciência e capacidade do presidente Cardoso, só poderá ser corrigida mediante profundas reformas partidária e institucional. É indispensável que se torne o voto popular politicamente representativo, através do regime distrital misto. É igualmente indispensável que se limite o número de partidos mediante a imposição de um mínimo significativo de votação popular, que se os conduza à adoção de consistente programa próprio, com disciplina partidária e que se os submeta ao requisito de uma maioria estável, em cada legislatura, submetida a uma liderança única, mediante coligações partidárias duráveis, se nenhum partido isoladamente adquirir tal maioria, sob pena de dissolução da Câmara e convocação de novas eleições.

O governo Cardoso, nos três anos que lhe restam de seu segundo mandato, tem de promover as reformas necessárias para que o país recupere efetiva estabilidade no balanço de pagamento e nas contas do setor público. Tem, por outro lado, de mobilizar a opinião pública e o Congresso no sentido de promover as reformas política e institucional que restaurem a governabilidade do país. Para esse efeito importa, concomitantemente, que uma eficaz implementação do Plano-Plurianual atenda aos aspectos mais imediatos da crise social e restaure a boa imagem pública do presidente. Não será possível atingir grandes objetivos substanciais de 2000 a 2003. Mas é possível tornar o país viável para enfrentar os grandes desafios do século XXI.

\section{Desafios do século XXI}

O futuro é sempre especificamente imprevisível. A continuada aceleração da história, desde o início dos tempos modernos, vertiginosamente a partir da Segunda Guerra mundial, torna particularmente impossível qualquer antecipação do que concretamente venha a ser o século XXI. Os dois principais fatores dessa imprevisibilidade são, por um lado, as extraordinárias inovações tecnológicas que estão surgindo e continuarão a surgir, com os efeitos que terão sobre a sociedade futura. Por outro lado, são os rumos que venha a seguir essa sociedade futura, não somente por causa do imprevisível impacto das inovações tecnológicas mas, principalmente, em função das profundas mudanças culturais que estão ocorrendo no âmbito de sociedades consumistas de massa, em detrimento de seus valores superio- 
res. Independentemente de outras circunstâncias, entretanto, duas grandes tendências podem ser identificadas com relação ao século entrante resultantes, por um lado, do processo de globalização e, por outro, da formação de uma nova ordem mundial.

O atual processo de globalização, sobre o qual já existe uma ampla literatura, caracteriza-se, como precedentemente ocorreu com os efeitos da revolução mercantil e da revolução industrial, por extrema assimetria, incomparavelmente superior à decorrente dos processos anteriores. Um restrito número de países e de grupos recolherá quase todos os benefícios da globalização. Alguns países e grupos - como poderá ser o caso do Brasil e da América do Sul, no âmbito de Mercosul - lograrão uma situação de equilíbrio. A grande maioria dos grupamentos humanos arcará com os custos desse processo. Custos múltiplos e variados, que importarão em amplo desemprego, em deslocamentos negativos de toda a sorte, em perda de identidade coletiva, e num desamparo geral dos indivíduos. Tais efeitos negativos, que serão, muitas vezes, concomitantemente acompanhados por uma elevação tecnologicamente induzida do nível de vida, decorrerão principalmente do fato de que as estruturas nacionais serão majoritariamente desarticuladas pelo processo de globalização, sem que, ao mesmo tempo, surjam instituições internacionais compensadoras. A grande maioria dos homens perderá sua cidadania nacional muito antes do momento em que se configure, de maneira estável, uma razoavelmente eqüitativa ordem mundial.

A formação de uma nova ordem mundial é o outro macroprocesso que se realizará no curso do século XXI. Deixou de existir, com a implosão da União Soviética, a ordem mundial bipolar que regulou o mundo na segunda metade do século XX. Em seu lugar, os Estados Unidos, única superpotência, estão exercendo uma hegemonia cada vez mais ampla e consolidada, impondo, ainda que de forma relativamente benigna, uma Pax Americana. Há importantes forças, dentro e fora dos Estados Unidos, que se opõem a essa hegemonia; China, Rússia e os mais importantes países do mundo islâmico, como Irã e Iraque, a ela resistem. Na União Européia, dividida entre uma posição atlântica (Grã Bretanha e países nórdicos) e uma posição europeista (países latinos, germânicos e eslavos), não é provável que as forças europeizantes alcancem suficiente predominância para conduzir a Europa a uma política externa e de defesa efetivamente independente. Assim sendo, a Pax Americana regulará o mundo ocidental no curso dos próximos decênios.

A partir de meados do século XXI, entretanto, é provável que a China adquira condições de equipolência com os Estados Unidos, tornando-se 
uma segunda superpotência. A Rússia, por seu lado, ter-se-á recuperado da grande crise de reestruturação, após a desagregação da União Soviética, e retornará à condição de superpotência. Em tal situação, tenderá, em distintas condições, a se reconstituir, em meados do século XXI, o bipolarismo da segunda metade do século precedente. Esse novo bipolarismo, num nível militar-tecnológico incomparavelmente mais elevado, tornará, ainda mais que o precedente, impossível um desfecho bélico. Impor-se-á, assim, a longo prazo, sob pena de suicídio coletivo do mundo, a necessidade de um compromisso de coexistência, que tenderá à formação de uma Pax Universalis, dentro das linhas genialmente imaginadas e preconizadas por Kant, em sua Paz Perpétua, de 1795.

Confrontado com essas duas grandes tendências que marcarão o século XXI, o Brasil nele ingressará trazendo, do século anterior, o imperativo de superar seu subdesenvolvimento e arcará, no curso do novo século, com o problema de enfrentar os efeitos negativos da globalização e, pelo menos na primeira metade do século, da Pax Americana.

Em tal situação, o que estará em jogo, para o Brasil, é a difícil preservação, nas futuras condições do mundo, de sua viabilidade nacional interna e externa. Como precedentemente se assinalou, a globalização favorecerá um restrito número de países e, para a grande maioria, desarticulará suas estruturas nacionais, sem satisfatórias compensações. A preservação, pelo Brasil, de sua viabilidade nacional no curso da primeira metade do século XXI dependerá, domesticamente, em primeiro lugar, da medida em que consolide sua integração social, eliminando nos dois próximos decênios a abissal brecha que separa a minoria educada e moderna das grandes massas deseducadas e primitivas. Dependerá, ademais, da medida em que administre competentemente o processo de globalização, preservando satisfatória margem de autonomia decisória e produtiva, ainda que incorporando capitais e tecnologias forâneos.

A preservação da autonomia externa do Brasil, no quadro de uma predominante Pax Americana, dependerá da medida em que logre consolidar Mercosul e expandi-lo para o conjunto da América do Sul, impedindo sua aniquilação pela ALCA e mantendo estreitos vínculos de cooperação com a Europa, com os grandes países asiáticos e islâmicos e um ativo regime de relações equilibradas e independentes com os Estados Unidos.

A desarticulação das estruturas nacionais, que tenderá a ser produzida pelo processo de globalização, particularmente nas áreas de predominância da Pax Americana, será tanto mais detrimental quanto mais numerosas sejam as populações atingidas. Os países africanos de grande população e 
muito deficiente estruturação nacional, como a Nigéria, já proporcionam, presentemente, suficientes indicações do que tende a ocorrer.

Se o Brasil lograr superar seu subdesenvolvimento até o horizonte do ano 2020, como lhe é perfeitamente possível, e se for satisfatoriamente administrado, mantendo taxas anuais de crescimento do PIB não inferiores a $5 \%$, poderá alcançar um PIB per capita, em 2020, da ordem de US\$ 15 mil. Se alcançar, nesse mesmo período, um satisfatório nível de integração social, como também lhe é perfeitamente possível, disporá de condições para preservar sua autonomia doméstica e poderá se assegurar, no âmbito de Mercosul, mediante apropriada política externa, um satisfatório grau de autonomia internacional. Isto significará assegurar ao povo brasileiro condições de se constituir como uma das grandes sociedades do século XXI e se habilitar - se o mundo não se suicidar com uma terceira guerra mundial - a ingressar, em boas condições, na segunda metade do século XXI, na era da Pax Universalis.

Helio Jaguaribe, cientista político, é decano do Instituto de Estudos Políticos e Sociais. 